\title{
Design and Implementation of Financial Engineering Application System based on Supply Chain Management Model
}

\author{
QiJing Li \\ \{ liqijingjx@126.com\} \\ Department of Economic Management, Heilongjiang University of Technology, jixi158100, China
}

\begin{abstract}
Supply chain management as a new management mode and method, in the new competitive environment, the value and competitiveness of enterprises in the same time, but also increased the risk of supply chain enterprises. Therefore, the research on supply chain risk management is very important in the new situation. This paper from two aspects: the concept of supply chain risk management, supply chain risk management study, risk identification, risk assessment, risk response three aspects, the related research results at home and abroad to summary and evaluation. Finally, the research put forward.
\end{abstract}

Keywords: Supply chain risk management; risk identification; risk assessment; risk response

\section{Introduction}

Supply chain management as a new management mode and method, in the new competitive environment, the value and competitiveness of enterprises in the same time, but also increased the risk of supply chain enterprises. Over the past few years, a variety of supply chain disruptions have made many companies suffer heavy losses. More and more cases show that, with the increasing complexity of modern supply chain, the vulnerability of supply chain is gradually increasing. Therefore, the research on supply chain risk management in the new situation is of great significance.

Supply chain refers to the acquisition of raw materials, processed into semi-finished products until the product, and the product to the customer in the hands of a number of enterprises or sectors of the network [1].

At present, the risk of supply chain, different experts and scholars have different understanding. Among them, Ding Weidong believes that the supply chain risk is a potential threat, it will use the vulnerability of the supply chain system, the supply chain system damage. From the point of view of the target control, it can be said that the supply chain risk is the possibility of supply chain deviation from the intended target. Hu Jinhuan believes that supply chain risk is refers to the supply chain enterprises in the production process, since all cannot be predicted in advance of uncertain factors, the influence of, enterprise supply chain actual income and expected income deviation, thereby the risk of damage and possibility. Zhang Cunlu believes that the main body of the supply chain, cross regional, multi link 
characteristics, so that the supply chain is vulnerable to adverse factors from the external environment and the internal chain, the formation of supply chain risk. Zhu Huaiyi argued that a variety of supply chain uncertainty in supply chain as a whole function disorder or even interrupted the phenomenon is defined for supply chain risk phenomenon, resulting in the possibility and the harm of this phenomenon is the supply chain risk.

At present, there is no uniform definition of risk management in supply chain, and many scholars have their own definitions. The Paulsson believes that supply chain risk management is and supply chain parties to work together or alone, the use of risk management tools to deal with those caused by logistics or related activities or the effects of supply chain risk and uncertainty. Ning Zhong believes that the supply chain risk management is defined by the risk in the supply chain and the supply chain to identify and manage the risk of external, to reduce the overall weakness of the supply chain. And Chapman and so on will be defined as: by coordinating the supply chain members, identify and manage the risk of internal and external supply chain, in order to reduce the vulnerability of the supply chain as a whole. C. S. Tang believes that supply chain risk management is the coordination or cooperation between supply chain partners to ensure the interests and continuity of supply chain node enterprises.

\section{Supply Chain Risk Management}

At present, the research on supply chain risk management is generally considered from three aspects: risk identification, risk assessment, risk response.

Supply chain risk identification is the first step of supply chain risk management. Firstly, the risk identification of supply chain is done well, so as to make the risk assessment and risk response based on this. Supply chain risk identification refers to the risk management of supply chain in various risk events before the use of a variety of methods to systematically understand the various risks faced by the risk and analysis of the potential causes of the occurrence of risk events [2].

To identify the risk of supply chain, it is mainly to classify the risk of supply chain, and the domestic and foreign scholars have put forward a lot of ways. Supply chain risk can be divided into three aspects, one is from the supply chain itself, such as Sang Shengju, etc. it is divided into: cooperation risk, information risk, moral risk, contract risk and external environment risk. Is itself, the risk characteristics of the division, such as Wu Jun can be divided into: daily risk, the risk of sudden, and pointed out that the probability of occurrence of the former, but is not harmful to, is easy to control; the latter occurring probability is small, but the harm of generally larger, and not easy to control. There is also a classification of the supply chain as a whole into consideration, divided into: endogenous risk and exogenous risk. Endogenous risk refers to the risk arising from the interaction among members of the supply chain, and the external risk refers to the risk arising from the interaction between the supply chain and the external environment of the supply chain. Among them, the endogenous risk includes supply chain partner risk, supply chain information risk, supply chain credit risk.

Risk identification, risk assessment and risk response will be completely different. Therefore, the correct identification of risk, for effective management of risk is essential.

\subsection{Risk Assessment}


Supply chain risk assessment is the estimation and measurement of the extent and scope of the occurrence of risk or loss. Risk identification is only the first step in the risk management, and it is necessary to estimate and measure the potential loss and the extent of the loss. In the supply chain risk assessment, it is not only to consider the impact of risk on the supply chain nodes, but also to consider the impact of risk on the whole supply chain. Loss resulting from a risk point of view, we should not only consider the economic loss caused by the risk, but also consider other losses brought about risk, such as trust invisible crisis, customer loss, corporate reputation, decrease losses [3].

At present, there are many methods of risk assessment, including Delphy Fa, analytic hierarchy process, grey correlation method and fuzzy comprehensive evaluation method. At the same time, many experts and scholars are also doing research on risk assessment of supply chain.

Ding Weidong et al. Proposed to measure the risk of supply chain system by calculating the reliability of the supply chain system. Using fuzzy risk factor analysis method to evaluate the risk of the supply chain, the basic idea is: comprehensive consideration of various supply chain risk factors determined the reliability degree of each risk factor, calculate the reliability of supply chain enterprises, and then calculate the reliability of the whole supply chain.

$\mathrm{Fu} \mathrm{Yu}$ et al the case reasoning technology in artificial intelligence is introduced supply chain risk estimation, can solve the case description and the storage organization, matching case retrieval, and the retrieval results of adjustment of key problems, design the practical abiogenesis risk estimation system prototype.

Liu Yongsheng and Bai Xiaojuan in analysis based on supply chain risk early warning index system design ideas, and put forward the supply chain risk early-warning index system design of four principles: the principle of combining sensitivity principle, flexibility principle, comprehensive principle, qualitative and quantitative indicators. Construction of the supply chain risk early warning index system, mainly includes four levels, seven comprehensive indicators. Finally, a comprehensive evaluation method of supply chain risk early warning based on analytic hierarchy process is presented.

Fang Fang and Shu Liangyou from the perspective of cooperative partnership to explore the manufacturer's risk assessment. On the basis of manufacturing partners risk source analysis, the paper discusses the steps of risk assessment, according to the principle of determining the index system established manufacturer partners risk evaluation index system and fuzzy comprehensive evaluation model. A comprehensive evaluation of the risk of manufacturers and sellers is carried out by means of examples.

In risk assessment, must be flexible use of various evaluation methods, learn from each other and from the different angle of evaluation, to come out with different evaluation methods of the results of synthesis, analysis and calculation, finally get the supply chain risk occurrence probability and the loss size, so as to the stage of risk response to develop feasible and reasonable measures, in order to provide the basis for risk management decisions.

\subsection{Risk Response}

The ultimate goal of risk management is to reduce or eliminate the disastrous consequences caused by various risks in the most economical and reasonable way. Therefore, after the completion of the supply chain risk assessment, the choice of the most appropriate method or the comprehensive plan to deal with risk is the inevitable choice of supply chain risk management. In the existing literature, the methods of supply chain risk management can be 
summarized into the following categories: avoidance, acceptance, sharing and transfer of risk [4].

Risk aversion is one of the most concerned by the academic and business circles. In this respect, the theory and the literature are also many. Hau and Seungjin (Hau, Seungjin, 2004) mainly from the perspective of the government's attention to the supply chain may be the risk of transport, especially in containers may contain weapons of mass destruction and other dangerous goods. They put forward the method of total quality management to manage the supply chain risk. Because of the risk of this kind of risk, it will have a very serious negative effect, so it must be prevented in advance. Including the method to avoid the risk of $\mathrm{J}$ ttner and Peck is put forward for:

Vertical integration of upstream and downstream chain; increased inventory and inventory buffers, etc., of which there are many managers need to be weighed, a supply chain management strategies may increase another risk in mitigating a risk at the same time. Sunil and ManMohan analysis various circumvention risk strategy for risk that: increase productivity can greatly ease the production delay, also has a role in the procurement risk, inventory risk, but will increase the risk of capacity, the risk of investment in production capacity; increase in inventory can also greatly ease of production delays, reduce supply chain disruption events, purchasing and production risks, but it will increase the inventory risk conclusion.

Acceptance risk refers to the risk that the enterprise should be accepted when a certain risk is not avoided or the risk of a larger benefit can be obtained. Acceptance risk is one of the most widely used methods in enterprises. Jiao Fangmin in the system of supply chain risk management research "mentioned enterprises receive the risk to risk than the much larger gains and risk cost, greater than the assumption of risks are required to pay the price etc. the case, it shall accept the risk.

\section{The Model of Supply Chain Risk Management}

Risk transfer refers to bear the risk of the subject itself may encounter losses or uncertain consequences passed on to others, the risk of processing way "although the risk transfer and the reasons for different means, but are trying to will be borne by himself the risk of loss and transfers undertakes by others. Zhou Qinyin in the supply chain risk management research "mentioned that implement the risk transfer strategy must adhere to the following principles, that take the initiative to take risks are corresponding interests, who has the ability to take risks let who bear; let a party is at fault, assume corresponding responsibility and risk. The strategy of transferring risk mainly includes selling, outsourcing, signing the contract of risk liability, insurance and guarantee, litigation.

At present, there is no uniform definition of risk management in supply chain, and many scholars have their own definitions. The Paulsson believes that supply chain risk management is and supply chain parties to work together or alone, the use of risk management tools to deal with those caused by logistics or related activities or the effects of supply chain risk and uncertainty. Ning Zhong believes that the supply chain risk management is defined by the risk in the supply chain and the supply chain to identify and manage the risk of external, to reduce the overall weakness of the supply chain. And Chapman and so on will be defined as: by coordinating the supply chain members, identify and manage the risk of internal and external supply chain, in order to reduce the vulnerability of the supply chain as a whole. C.S.Tang 
believes that supply chain risk management is the coordination or cooperation between supply chain partners to ensure the interests and continuity of supply chain node enterprises.

In essence, supply chain risk management is to realize the goal of supply chain management, emphasize the whole benefit of the supply chain, and pursue the whole optimal but not the local optimum. Therefore, only the establishment of risk management based on the supply chain management is the core of ideological basis in order to realize the effective supply chain risk management, and the core idea is to using system view, establish the member enterprises in the supply chain risk coordination mechanism, realize the cooperative control, and promote the further development of the research on supply chain risk management. Future research can begin from the following aspects:

Firstly, the risk management of supply chain network from the network perspective. The traditional risk management theory emphasizes the two elements of risk: the possibility and severity. This makes the risk identification, risk assessment and risk control strategy of the center of gravity is equally placed in risk prevention (that is, the possibility of reducing the occurrence of the event) as well as the risk of weakening (that is, to reduce the severity of the event). However, with the advance of globalization, some risks are unpredictable and can not be completely prevented. Instead, from the macroscopic angle optimization of supply chain network structure and to establish a rapid response system to make the supply chain more flexible, reliable and flexible as possible, enhance the immune ability, realize the sustainable management of the business. At the same time, network theory can reveal the macro structural characteristics of a supply chain network from the macro level, studying the supply chain network evolution and growth process, analysis of supply chain network stability and ability to resist risks, which is the previous research on supply chain management can not complete the task. Therefore, on the complex networks theory as the theoretical basis, to network analysis as a tool, the use of theory and practice combination, a combination of qualitative and quantitative methods of supply chain risk management research is one of the important research directions in the future [5].

The second is the research of supply chain risk coordination mechanism. At present, the supply chain management synergy mechanism of CPFR, future studies need these thoughts will be extended to the field of supply chain risk management, studies how to design and build collaborative supply chain risk management system and how to establish a collaborative decision-making process make supply chain members can work together to respond to and control risk.

\section{Conclusion}

This paper mainly studies the evolution process of supply chain risk. Risk can be transmitted through the supply chain, but the research on its infection law and control strategy has not been found in the existing literature. At present, the complex and dynamic business environment supply chain uncertainty increases, the supply chain risk emergency response is increasingly urgent and important, while the supply chain evolution of risk control and decision is the emergency response management important content and premise, but also the need for one of the directions of further research. 


\section{References}

[1] Zhu Huaiyi, Zhu Daoli et al. Analysis of. Soft science of supply chain risk factors based on uncertainty, Vol. 20, No. 3. (2016)

[2] U. Supply Paulsson chain risk management. In: Brindley C. Supply Chain Risk. Ashgate Publishing Limited, pp. 79-96. (2014)

[3] Ning Zhong. The influence factors of the vulnerability of supply chain and its management principles. China's circulation economy, No. 4, pp. 13-16. (2014)

[4] Petal Identifying and Managing Chapman Supply ChainVulnerability. Logistics and Transport Focus, Vol. 4, No. 4, pp. 59 64. (2012)

[5] Perspectives in supply Christopher. S. Tang. Chain risk management. Production Economics. March, (2015) 